\title{
Efeitos da poluição por petróleo na estrutura da folha de Podocarpus lambertii Klotzsch ex Endl., Podocarpaceae
}

\author{
Leila Teresinha Maranho ${ }^{1,3}$, Franklin Galvão², Karla Heloise Preussler ${ }^{1}$, Graciela Inez Bolzon de Muñiz ${ }^{2}$ e \\ Yoshiko Saito Kuniyoshi ${ }^{2}$
}

Recebido em 6/06/2005. Aceito em 16/02/2006

\begin{abstract}
RESUMO - (Efeitos da poluição por petróleo na estrutura da folha de Podocarpus lambertii Klotzsch ex Endl., Podocarpaceae). Podocarpus lambertii, popularmente conhecida como pinheiro-bravo é uma Podocarpaceae típica da região Sul do Brasil, família que se distingue de outras coníferas por possuir uma estrutura de suporte para o óvulo denominada "epimatium". O presente estudo teve como objetivo investigar, por meio de parâmetros morfológicos e anatômicos, os efeitos da poluição por petróleo na estrutura das folhas de Podocarpus lambertii Klotzsch ex Endl. (Podocarpaceae), popularmente conhecida por pinheiro-bravo. As folhas foram coletadas no município de Araucária, Paraná, Brasil, na Refinaria de petróleo Presidente Getúlio Vargas (REPAR) um ano após exposição à poluição provocada pelo derramamento de petróleo. Esta espécie foi selecionada, porque além de ser nativa, apresentou um comportamento diferenciado dentre as demais diante da poluição. Folhas de nove indivíduos (seis expostos ao petróleo e três controle) foram coletadas. Foram avaliadas em microscopia fotônica as dimensões foliares (comprimento, largura e área foliar), a espessura dos tecidos e a densidade estomática. Os dados obtidos foram analisados estatisticamente. Nos indivíduos expostos à poluição, a superfície foliar foi menor, a densidade estomática e espessura dos tecidos foliares foram maiores quando comparados aos indivíduos controle. Os resultados obtidos permitem concluir que $P$. lambertti reagiu quando de sua exposição à poluição por petróleo.
\end{abstract}

Palavras-chaves: Podocarpus lambertii, Podocarpaceae, poluição, petróleo, anatomia foliar

\begin{abstract}
Effects of oil pollution on leaf structure of Podocarpus lambertii Klotzsch ex Endl., Podocarpaceae). Podocarpus lambertii, locally known as "pinheiro-bravo", is a typical Podocarpaceae from Southern Brazil. This family is the most diverse of conifers; it has a distinguishing characteristic, namely the presence of an ovule support structure, called an epimatium. The aim of this study was to investigate the effect of oil pollution on the leaf structure of P. lambertii through morphology and anatomy. Leaves were collected in Araucária Municipality, Paraná, Brazil, at the Presidente Getúlio Vargas Petroleum Refinery one year after they had been exposed to pollution by an oil spill. This species was studied because besides being a native species, it behaved differently from the other species when faced with pollution. Nine individuals were selected (six exposed to pollution and three controls). We analyzed the leaf surface (length, width and leaf area), tissue thickness and stomatal density using light microscopy. The data were statistically analyzed. Leaf anatomy was rather variable. The individuals that were exposed to pollution had smaller leaf surfaces, while stomatal density and thickness of leaf tissues were greater when compared to the control.
\end{abstract}

Key words: Podocarpus lambertii, Podocarpaceae, pollution, petroleum, leaf anatomy

\section{Introdução}

O petróleo, originado da transformação de grandes deposições fósseis, é uma mistura de composição variável, formada por uma fração polar, os asfaltenos e resinas (Huesemann 1994; Dorn et al. 1998) e, predominantemente por hidrocarbonetos (saturados e aromáticos), além de baixas concentrações de $\mathrm{Ni}, \mathrm{Fe}$ e Vn (Freedman 1995).

Segundo Sloan (1999), após entrar em contato com o ambiente, o petróleo sofre alterações nas suas características originais, devido a fatores físicos e principalmente biológicos (biodegradação). As transformações físicas e biológicas são reguladas pelas características específicas do derramamento e do ambiente atingido, desta forma, este último tem grande influência no grau de impacto. Michel et al. (2002; 2005) afirmam que o petróleo constitui um poluente que pode persistir no ambiente por um longo período, até que a vegetação se recupere totalmente, e que a sua persistência pode ser explicada pela lenta biodegradação dos hidrocarbonetos.

\footnotetext{
1 Centro Universitário Positivo, Rua Prof. Pedro Viriato Parigot de Souza 5300, 81280-330 Curitiba, PR, Brasil

2 Universidade Federal do Paraná, Departamento de Ciências Florestais, Rua Lothário Meissner 3400, 80210-170 Jardim Botânico, Curitiba PR, Brasil

3 Autor para correspondência: maranho@unicenp.br
} 
Os efeitos crônicos da poluição com petróleo são pouco conhecidos (Strickland 1990). Spies et al. (1996) citam que os efeitos tóxicos imediatos tendem a ser causados principalmente por moléculas de baixa massa molar e que se degradam rapidamente. Já os efeitos tóxicos crônicos são devido às moléculas de alta massa molar, geralmente aromáticas, que apresentam menor toxicidade, mas são persistentes, causando efeitos mais duradouros. Os hidrocarbonetos produzem efeitos nocivos aos animais e plantas (Pothuluri \& Cerniglia 1994; Dorn et al. 1998; Lin \& Mendelssohn 1998; Dorn \& Salanitro 2000). A inibição da germinação e a diminuição do crescimento vegetal, bem como a morte das plantas são indicadores da toxicidade dos hidrocarbonetos (Powell 1997; Rivera-Cruz et al. 2002; Hernandez-Valencia \& Magger 2003; Rivera-Cruz \& Trujillo-Narcía 2004).

Embora os hidrocarbonetos do petróleo sejam poluentes ambientais difundidos e a sua biodegradação seja assunto central de numerosas investigações, as informações sobre a sua toxicidade às plantas no solo são limitadas. A reação de algumas plantas como aveia (Avena sativa L.), centeio (Secale cereale L.) e cevada (Hordeum vulgare L.), quando da contaminação do solo e da água com os produtos do petróleo, foi estudada por Petukhov et al. (2000). Estes autores relatam os efeitos negativos da contaminação sobre a germinação de sementes, diminuição da biomassa total e do comprimento das raízes. Os mesmos sugerem que estas plantas poderiam ser empregadas como organismos-teste para análise da toxicidade deste poluente no solo e na água.

Baek et al. (2004) quando da investigação dos efeitos fitotóxicos do óleo bruto e de seus componentes no crescimento do feijoeiro (Phaseolus nipponensis Ohwi) e do milho (Zea mays L.), observaram que a fitotoxicidade elevou-se com o aumentou do número de anéis aromáticos, e que as plantas de Z. mays demonstraram maior sensibilidade ao solo contaminado com hidrocarbonetos poli-aromáticos, quando comparadas com as de P. nipponesis. Outro estudo realizado sobre o efeito do derramamento de óleo sobre plantas de Zea mays L., realizado por Ekundayo et al. (2001), revelou uma redução no crescimento desta espécie em solos poluídos, usando como indicadores do crescimento a altura para planta, largura do caule e área da folha.

O estudo do comportamento de plantas em solos contaminados com petróleo permite identificar e selecionar espécies fito-indicadoras de tal contaminação. Para obter indicadores da fitotoxicidade do petróleo em solos, é necessário identificar a sensibilidade de plantas nativas (Rivera-Cruz \& Trujillo-Narcía 2004). Os trabalhos relacionados ao efeito do solo contaminado por petróleo nas plantas avaliam, principalmente, parâmetros como a germinação e crescimento vegetal, sendo assim, o que se observa é a inexistência de estudos sobre os efeitos deste poluente sobre a estrutura vegetal interna. Desta forma, o presente estudo foi desenvolvido com o objetivo de avaliar os efeitos da poluição por petróleo na estrutura da folha de Podocarpus lambertii Klotzsch ex Endl. (pinho-bravo) que permaneceu viva após um ano do derramamento de petróleo no solo, enquanto que a maioria das outras espécies do mesmo local não suportaram a exposição ao poluente e morreram imediatamente.

\section{Material e métodos}

O material estudado, folhas de Podocarpus lambertii, foi coletado na Refinaria de Petróleo Presidente Getúlio Vargas (REPAR) localizada em Araucária, Região Metropolitana de Curitiba, entre as coordenadas geográficas $25^{\circ} 34^{\prime} 02,5^{\prime}$ 'S e 49²0'53,5”W. Este local foi atingido por acidente ambiental, quando foram derramados quatro milhões de litros de petróleo no solo. A região compreende uma área de encosta, onde o relevo é ondulado e os solos mais ressecados. Nesta área houve a infiltração de petróleo em profundidade e o seu escoamento até a planície, onde o relevo é plano. A vegetação é constituída por estágios sucessionais secundários da Floresta Ombrófila Mista (Floresta com Araucária), e parte dela, que foi atingida diretamente pelo vazamento, teve seus estratos arbóreo, arbustivo e herbáceo quase que integralmente dizimados.

Foram selecionados nove indivíduos com altura entre 5 e $8 \mathrm{~m}$, sendo seis em área atingida pela contaminação por petróleo e, três indivíduos controle, nas ilhas com vegetação não atingida pelo petróleo. As coletas foram realizadas um ano após o acidente ambiental. De cada indivíduo foram coletadas 60 folhas, totalmente expandidas e posicionadas a partir do $4^{\circ}$ ramo, na região mediana dos ramos e com exposição à luminosidade no sentido leste. As folhas dos indivíduos controle foram coletadas nas regiões mais jovens das plantas.

O material coletado para a análise das dimensões foliares foi herborizado; e aquele utilizado na para o estudo da estrutura interna da folha e determinação da densidade estomática foi fixado com FAA 70 por $48 \mathrm{~h}$ (Johansen 1940) e, posteriormente, mantido em 
etanol $70 \%$ até o processamento final (Berlyn \& Miksche 1976).

Os dados das dimensões foliares $\mathrm{em} \mathrm{cm}^{2}$ (comprimento, largura e área foliar) foram obtidos a partir de 20 folhas de cada indivíduo, de acordo com o método proposto por Kraus \& Arduim (1997).

Para determinar a densidade estomática por $\mathrm{mm}^{2}$ foram selecionadas amostras da região mediana de 20 folhas de cada indivíduo que foram diafanizadas (Franklin 1946) e coradas com azul de toluidina 0,05\% (Sakai 1973). As lâminas foram montadas com glicerina e a lutagem foi feita com esmalte incolor. Foi realizada uma contagem por folha em uma área de $1 \mathrm{~mm}^{2}$.

Para a confecção do laminário foram obtidas amostras de folhas de nove indivíduos, uma amostra por indivíduo. Estas foram incluídas em metacrilatoaglicol (JB-4) adotando-se o procedimento descrito por Feder \& O'brien (1968) e as especificações do fabricante (POLYSCIENCES INC). O seccionamento foi realizado em micrótomo de rotação (LEICA RM2125), com espessura de $7 \mu \mathrm{m}$, sendo as secções coradas com azul de toluidina $0,05 \%$, em tampão fosfato $0,1 \mathrm{M}(\mathrm{pH} 6,8)$, conforme $\mathrm{O}$ ' Brien et al. (1965). As lâminas permanentes foram montadas com resina sintética $\left(\right.$ Entelan $\left.^{\circledR}\right)$. A descrição das secções transversais e paradérmicas, assim como a contagem dos estômatos foi feita usando-se o microscópio fotônico (OLYMPUS - CX41RF) acoplado à câmara clara. $\mathrm{O}$ fotomicroscópio (OLYMPUS - BX 41) foi utilizado para obtenção das ilustrações, sendo as escalas obtidas nas mesmas condições das fotos. Foram realizadas duas mensurações dos caracteres morfométricos por folha, em microscópio invertido (OLYMPUS - IX50/IX70) com captura de imagem pelo software (IMAGE - PROPLUS).

A estatística descritiva foi realizada utilizando-se o programa Excel, da Microsoft, 2000. Para o estudo estatístico dos resultados foi utilizado o programa STATISTICA for Windows da Stasoft, onde verificou-se o padrão das distribuições por meio do teste Shapiro-Wilk. Para as variáveis com distribuição normal foram então realizadas inferências por meio de testes paramétricos, teste "t-student". Para as variáveis sem distribuição normal utilizou-se o teste não-paramétrico "Mann-Whitney U”.

\section{Resultados e discussão}

Dimensões foliares - As folhas de Podocarpus lambertii são simples, glabras, de forma lanceolada, com ápice obtuso, textura coriácea, venação uninérvea e filotaxia espiralada. As folhas dos indivíduos não expostos à poluição possuem, aproximadamente, $8,0 \mathrm{~cm}$ de comprimento, $0,5 \mathrm{~cm}$ de largura e $4,5 \mathrm{~cm}^{2}$ de área. Estas informações coincidem com as citadas por Macedo \& Leite (1999). Nas folhas coletadas em indivíduos expostos à poluição por petróleo, constatou-se a redução nas dimensões foliares, de aproximadamente, $75 \%$ no comprimento, $40 \%$ na largura e 78\% na área foliar (Tab. 1). No entanto, não foram constatados sintomas visíveis, como necrose ou clorose, nestas folhas.

Tabela 1. Médias \pm desvios-padrão das dimensões foliares (comprimento, largura e área foliar) de Podocarpus lambertii Klotzsch ex Endl. de indivíduos controle $(n=60)$ e expostos ao petróleo $(\mathrm{n}=120)$.

\begin{tabular}{lccc}
\hline Indivíduos & \multicolumn{3}{c}{ Dimensões foliares } \\
\cline { 2 - 4 } & $\begin{array}{c}\text { Comprimento } \\
(\mathrm{cm})\end{array}$ & $\begin{array}{c}\text { Largura } \\
(\mathrm{cm})\end{array}$ & $\begin{array}{c}\text { Área } \\
\left(\mathrm{cm}^{2}\right)\end{array}$ \\
\hline Controle & $8,03^{\mathrm{a}} \pm 0,64$ & $0,55^{\mathrm{a}} \pm 0,05$ & $4,46^{\mathrm{a}} \pm 0,06$ \\
Poluição & $2,83^{\mathrm{b}} \pm 0,71$ & $0,34^{\mathrm{b}} \pm 0,84$ & $0,98^{\mathrm{b}} \pm 0,33$ \\
\hline
\end{tabular}

Valores seguidos por letras diferentes são significativos ao nível de $5 \%$ de probabilidade $(\mathrm{p}<0,05)$.

A diferença nas dimensões foliares dos indivíduos dos dois locais de coleta pode estar refletindo a capacidade de otimização do "tamanho" foliar em relação ao meio. Desta forma pode-se sugerir que, os indivíduos coletados nos locais atingidos pelo petróleo sofreram uma adaptação, isto é, reduziram a superfície de perda de água por transpiração. Este fato pode estar refletindo a resposta das plantas à escassez de água, pois segundo Xu \& Johnson (1995); Hester \& Mendelssohn (2000); Pezeshki et al. (2000), a contaminação por petróleo afeta o desenvolvimento das plantas devido a diferentes efeitos físicos. Estes autores citaram como principal efeito físico, a película de petróleo que se forma cobrindo as raízes, alterando assim, a absorção de água e nutrientes. Bona \& Santos (2003) afirmam que o petróleo diminui a capacidade de retenção de água do solo, interferindo desta forma, no crescimento das plantas.

Kozlowski et al. (1991) comentam que um dos efeitos mais drásticos do estresse hídrico é a redução na área foliar, levando a um decréscimo na fotossíntese e, conseqüentemente, no crescimento. A tendência à redução foliar, observada em indivíduos de $P$. lambertii da área poluída, assemelha-se aos resultados obtidos por Inoue \& Reissmann (1993), para as plantas de 
Ligustrum lucidum W.T. Aiton coletadas em ambientes poluídos e por Proffitt et al. (1995) para as folhas de Rhizophora mangle L. crescendo em ambiente contaminado com petróleo. Martínez-Trinidad et al. (2002) em estudo realizado com Pinus leiophylla Schiede ex Schltdl. \& Cham. revelam que as folhas desta espécie apresentaram uma redução da área foliar sob condições de estresse hídrico. Segundo Esau (1998), a relação volume-superfície em folhas de ambientes onde ocorre escassez de água é elevada, ou seja, elas são pequenas e compactas. Esse caráter pode ser determinado por alguns tecidos internos, como por exemplo, mesofilo espesso, com parênquima paliçádico com células mais alongadas.

Estrutura frontal da epiderme e densidade estomática - A epiderme de ambas as faces é glabra. A face adaxial é constituída por células alongadas com paredes primárias retas, à ligeiramente curvas, com muitos campos de pontoação primária. Esse mesmo aspecto foi observado na epiderme da face abaxial, além da presença de estômatos dispostos em fileiras longitudinais descontínuas, caracterizando a folha desta espécie como hipoestomática. A densidade estomática média constatada nas folhas foi de, aproximadamente, 85 estômatos por $\mathrm{mm}^{2}$ para os indivíduos controle e de 125 estômatos por $\mathrm{mm}^{2}$ para os indivíduos expostos à poluição (Tab. 2 e Fig. 1-2).

Podocarpus lambertii exibiu uma tendência ao aumento no número de estômatos, provavelmente, como uma resposta às condições de estresse hídrico.
Tabela 2. Médias \pm desvios-padrão da densidade estomática e da espessura da cutícula (região do mesofilo) das folhas de Podocarpus lambertii Klotzsch ex Endl. de indivíduos controle $(\mathrm{n}=60)$ e expostos ao petróleo $(\mathrm{n}=120)$.

\begin{tabular}{lcc}
\hline Indivíduos & $\begin{array}{c}\text { Densidade } \\
\text { estomática }\left(\mathrm{mm}^{2}\right)\end{array}$ & $\begin{array}{c}\text { Espessura } \\
\text { da cutícula }(\mu \mathrm{m})\end{array}$ \\
\hline Controle & $84,60^{\mathrm{a}} \pm 10,55$ & $2,83^{\mathrm{a}} \pm 0,66$ \\
Poluição & $124,76^{\mathrm{b}} \pm 23,64$ & $4,89^{\mathrm{b}} \pm 1,27$ \\
\hline
\end{tabular}

Valores seguidos por letras diferentes são significativos ao nível de $5 \%$ de probabilidade $(\mathrm{p}<0,05)$

Esta característica, densidade estomática, tem sido amplamente estudada e relacionada a muitos fatores ambientais (Klich 2000). No entanto, a freqüência estomática não pode ser relacionada apenas com a transpiração, e sim com as condições do ambiente no qual as plantas se encontram como, por exemplo, a umidade, a alta concentração de poluentes (Woodward 1987; Musselman \& Minnick 2000) e a temperatura (Momen et al. 1999) entre outros. De acordo com Mauseth (1988); Fahn \& Cutler (1992), a densidade estomática fornece uma importante resposta, quando relacionada à baixa disponibilidade hídrica. Mauseth (1988) cita que o aumento na densidade estomática pode estar relacionado a uma maior eficiência nas trocas gasosas, no período em que os estômatos estão abertos. Já Larcher (2000) afirma que esta alteração adaptativa oferece condições para uma redução mais rápida da transpiração, por meio da regulação do fecha-
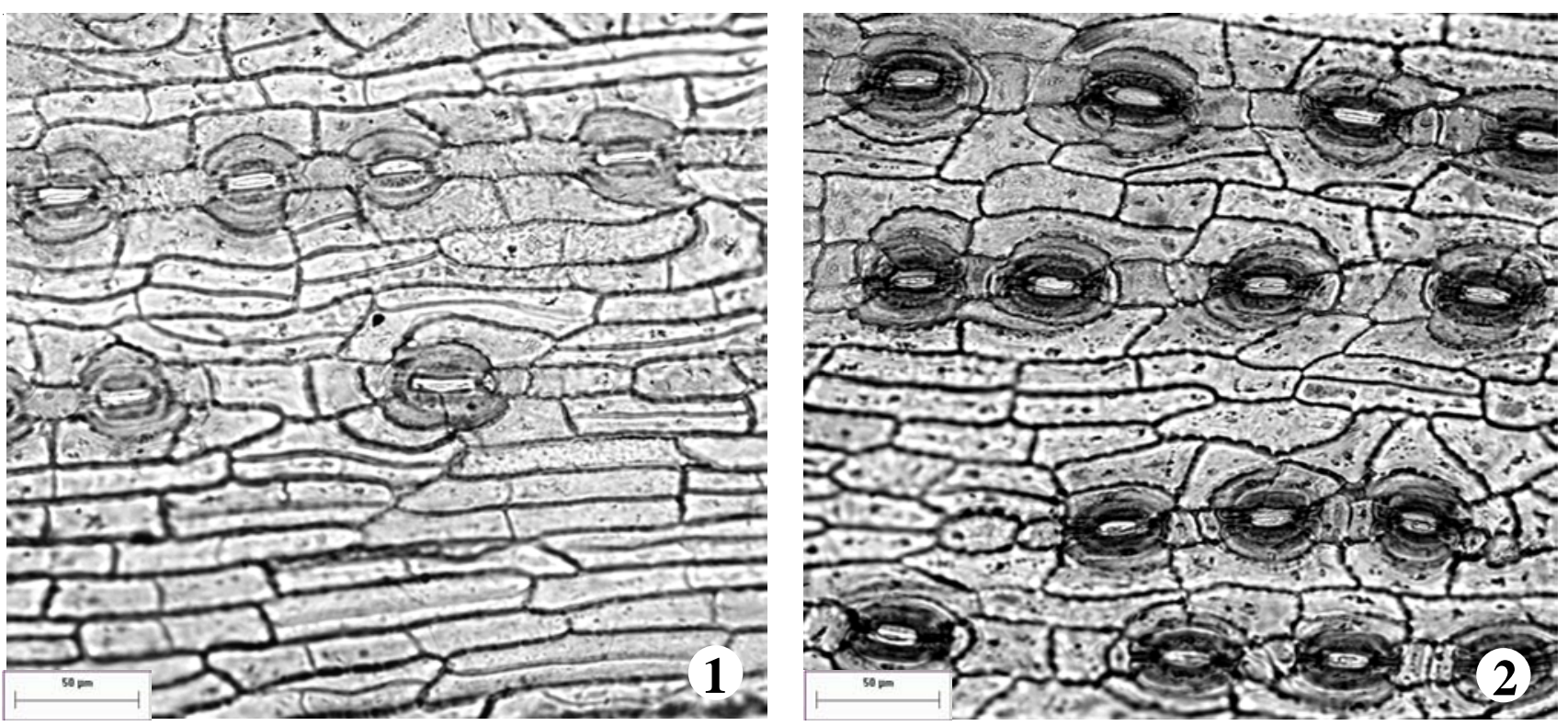

Figuras 1-2. Vista frontal da epiderme da face abaxial da folha de Podocarpus lambertii Klotzsch ex Endl. 1. Indivíduo controle. 2. Indivíduo exposto à poluição. 
mento estomático. Balaganskaya \& Kudrjavtseva (1998) afirmam que o grau de xeromorfia das folhas altera-se quando a planta está sujeita à poluição, podendo ser observado principalmente no aumento do número de estômatos.

Segundo Esau (1998), a alta freqüência estomática pode indicar uma reação ao estresse ambiental, Kozlowski \& Pallardy (1997) citam que a tolerância das plantas à poluição está rigorosamente correlacionada com a condutância estomática, e refere-se ao tamanho e, principalmente, à freqüência dos estômatos. Ferdinand et al. (2000) relata, ainda, que a elevada densidade estomática pode conduzir ao aumento da absorção de dióxido de carbono pelas folhas.

Estrutura e espessura do limbo - Em secção transversal, todas as células da epiderme, tanto adaxial quanto abaxial, apresentam-se bastante cutinizadas. $\mathrm{O}$ maior espessamento da cutícula (Tab. 2 e Fig. 3-4) observado nas folhas de indivíduos coletados na região de exposição ao petróleo, pode estar refletindo uma tendência destes indivíduos, em evitar a evapotranspiração excessiva. Vários são os autores, dentre eles, Mauseth (1988); Fahn (1990); Gifford \& Foster (1998), que afirmam que a espessura da cutícula é influenciada pelas condições ambientais e que a cutícula desempenha papel importante na redução da transpiração das plantas. Esau (1998); Larcher (2000) citam que além de uma cutícula mais espessa, as folhas de plantas que crescem em ambientes onde ocorre a escassez de água, podem ainda, apresentar as paredes celulares mais espessas, especialmente a parede das células epidérmicas, como um impedimento a evapotranspiração excessiva.

Em P. lambertii, os estômatos situam-se no mesmo nível da epiderme, são parcialmente recobertos pelas células subsidiárias e apresentam uma ampla câmara subestomática (Fig. 6). Buvat (1989) revela que nas folhas de coníferas e em muitas espécies adaptadas à seca e forte luminosidade, os estômatos localizam-se em depressões abaixo da superfície da folha. Abaixo da epiderme, observa-se a presença de hipoderme composta por 1-2 estratos de células com paredes celulares secundárias e lignificadas (Fig. 3-4). $\mathrm{Na}$ face abaxial a hipoderme é interrompida abaixo dos estômatos (Fig. 6). A presença de cutícula espessa, especialmente sobre as paredes das células subsidiárias, e de uma camada subepidérmica fibrosa, composta por células esclerificadas abaixo da epiderme, exceto sob os estômatos, nas folhas de coníferas é citada por Fahn (1990), Bell \& Hemsley (2000); Gifford \& Foster (1998). Feller (1996) cita que esta camada subepidérmica contribui, de forma significativa, para evitar a perda de água por transpiração quando a taxa de metabolismo é limitada.

O mesofilo em $P$. lambertii é dorsiventral (Fig. 5-6), porém nas folhas dos indivíduos expostos à poluição constatou-se a presença de mesofilo isolateral (Fig. 7). Na face adaxial, o parênquima paliçádico possui células retangulares, maiores e mais justapostas do que as células deste tecido na face abaxial. Nas folhas dos indivíduos expostos ao petróleo, observou-se um aumento no espessamento das folhas (Tab. 3), este fato se deve, principalmente, ao alongamento das células do parênquima paliçádico e em algumas regiões do limbo, a formação de 2-3 camadas deste tecido (Fig. 7). O restante do mesofilo é preenchido pelo parênquima lacunoso, constituído por células de tamanhos variados e com espaços intercelulares evidentes (Fig. 5-7). Mauseth (1988) reconhece a presença de parênquima paliçádico e lacunoso para as espécies do gênero Podocarpus L'Hér. ex Pers., diferente do observado em Pinus L. onde o mesofilo consiste apenas de duas ou três de parênquima clorofiliano plicado. No mesofilo de P. lambertii, observa-se ainda, o tecido de transfusão acessório (TTA) formado por traqueídes (Fig. 5-7). Conforme relatado por Griffith (1957) e por Esau (1985) para Podocarpus, por Lee (1952) para Dacrydium Lamb. e para as Cycas L. por Lereder (1955), o tecido de transfusão acessório (TTA) é constituído por células alongadas e de paredes espessas que se estendem para fora da bainha do feixe, em direção ao mesofilo, e não tem contato com o tecido de transfusão do feixe vascular. Segundo estes autores, a origem e função deste tecido de transfusão acessório não estão bem definidas, mas supõe-se que teria um papel importante na translocação de nutrientes entre os feixes vasculares e o tecido adjacente.

Fahn (1990) afirmou que a redução da área foliar é compensada pelo maior espessamento das folhas, o parênquima clorofiliano paliçádico torna-se mais desenvolvido que o esponjoso. Esta alteração pode influir no processo fotossintético, aumentando a sua eficiência, uma vez que a grande maioria dos cloroplastos encontra-se nas células em paliçada.

De acordo com Klich (2000), Kürschner et al. (1998), o aumento da espessura da folha está relacionado ao aumento dos tecidos do mesofilo. Klich (2000) afirma que esta característica reflete um mecanismo estrutural que potencializa a fotossíntese por unidade de área foliar e habilita a uma maior eficiência no uso da água. Kürschner et al. (1998) em 

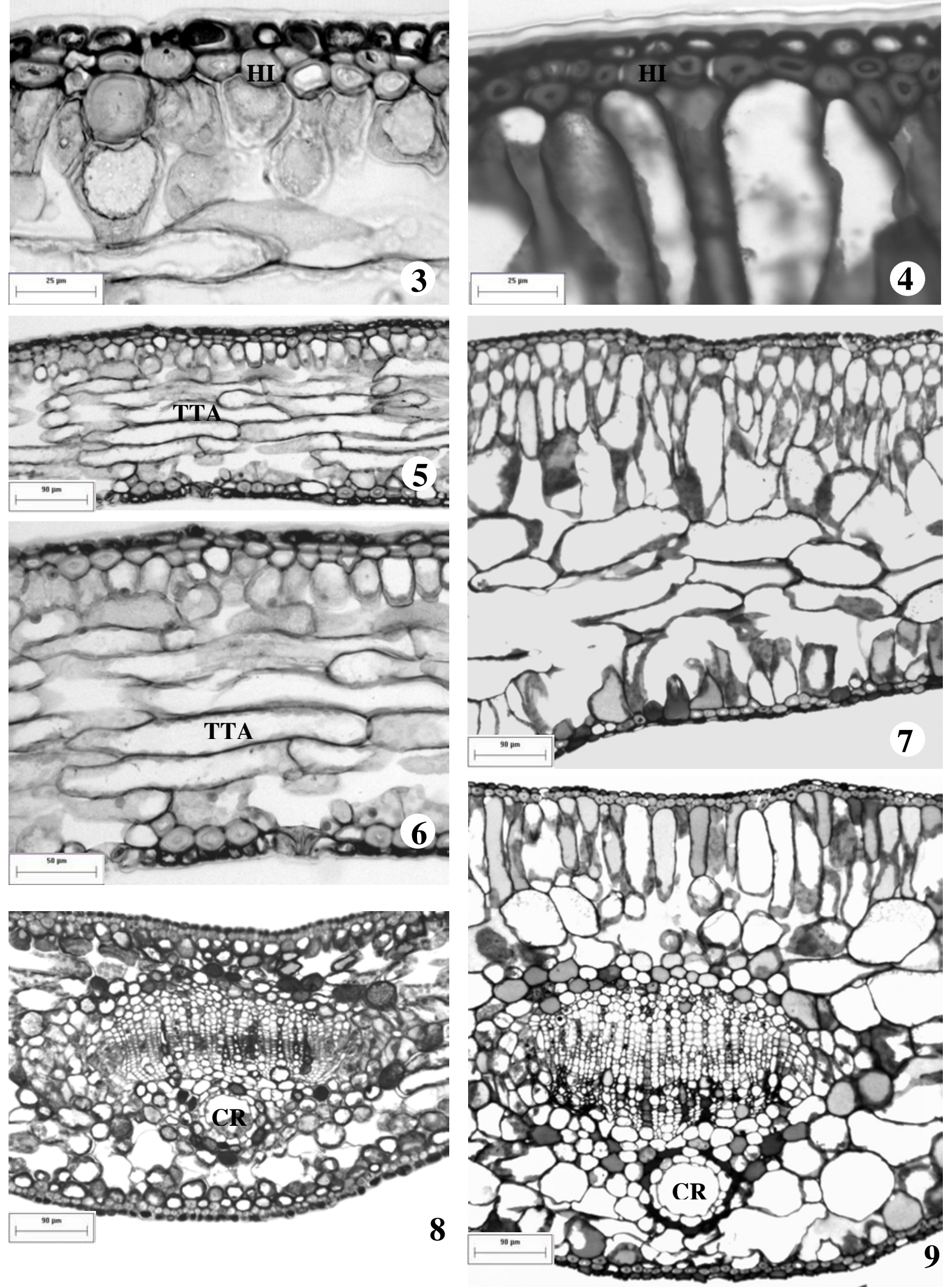

Figuras 3-9. Secções transversais da folha de Podocarpus lambertii Klotzsch ex Endl. 3. Detalhe da cutícula e hipoderme de indivíduo controle. 4. Detalhe da cutícula e hipoderme de indivíduo exposto à poluição. 5-6. Limbo de indivíduo controle. 7. Limbo de indivíduo exposto à poluição. 8-9. Nervura de indivíduos controle e exposto à poluição, respectivamente. HI - hipoderme, TTA - tecido de transfusão acessório, CR - canal resinífero. 
Tabela 3. Médias \pm desvios-padrão da espessura dos tecidos foliares de Podocarpus lambertii Klotzsch ex Endl. de indivíduos controle $(\mathrm{n}=60)$ e expostos ao petróleo $(\mathrm{n}=120)$.

\begin{tabular}{lccc}
\hline \multirow{2}{*}{ Indivíduos } & \multicolumn{3}{c}{ Espessura dos tecidos da folha $(\mu \mathrm{m})$} \\
\cline { 2 - 4 } & Nervura & Limbo & Mesofilo \\
\hline Controle & $603,61^{\mathrm{a}} \pm 24,06$ & $236,50^{\mathrm{a}} \pm 22,48$ & $221,12^{\mathrm{a}} \pm 23,08$ \\
Poluição & $410,54^{\mathrm{b}} \pm 139,19$ & $413,18^{\mathrm{b}} \pm 103,04$ & $395,65^{\mathrm{b}} \pm 101,93$
\end{tabular}

Valores seguidos por letras diferentes são significativos ao nível de $5 \%$ de probabilidade $(\mathrm{p}<0,05)$

estudo realizado com folhas de Quercus petrae (Matt.) Liebl., revelam que o alongamento das células do parênquima paliçádico reduz em aproximadamente, $35 \%$ os espaços intercelulares no mesofilo. A difusão através de espaços intercelulares pode ser importante na assimilação fotossintética de carbono, especial- mente em folhas hipoestomáticas, resultando na redução de $25 \%$ ou mais no ganho de carbono.

O sistema vascular é constituído por um só feixe mediano, com os elementos de xilema e de floema dispostos em séries radiais (Fig. 8-11). Associado ao tecido vascular, identifica-se o tecido de transfusão que é constituído principalmente de dois tipos de células parenquimáticas com paredes não lignificadas e traqueídes de paredes delgadas, porém, lignificadas e com pontoações areoladas. Segundo Mauseth (1988); Esau (1998); Fahn (1990); Gifford \& Foster (1998), uma das peculiaridades das folhas de coníferas é a presença do tecido de tranfusão que acompanha os feixes vasculares e, é composto por traqueídes, parênquima e células albuminosas. Próximo ao floema é possível observar a presença de canal resinífero (Fig. 8-9). Esau (1998) e Napp-Zinn (1966) citado por
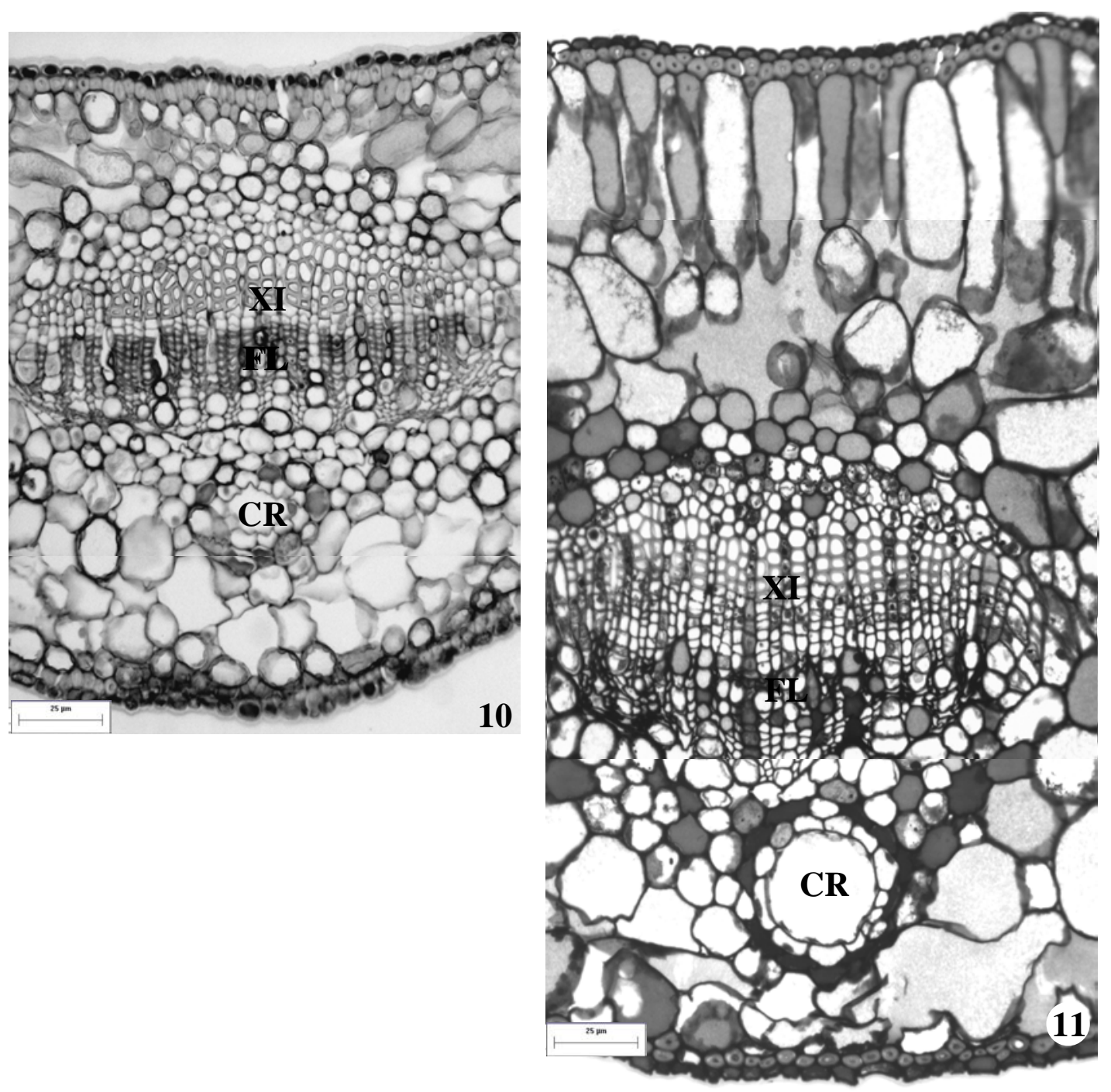

Figuras 10-11. Secções transversais da nervura da folha de Podocarpus lambertii Klotzsch ex Endl. Detalhe do feixe vascular. 10. Indivíduo controle. 11. Indivíduo exposto à poluição. CR - canal resinífero, FL - floema, XI - xilema. 
Page (1990) revelam que uma característica anatômica marcante desta espécie é a presença de canais resiníferos localizados na nervura, entre os tecidos de condução e a epiderme da face abaxial da folha. Os dados obtidos pela mensuração da nervura das folhas coletadas em ambiente poluído, revelaram um aumento, em média, de 32\% em sua espessura (Tab. 3 e Fig. 8-11).

Larcher (2000) afirma que para evitar à dessecação, plantas submetidas ao estresse hídrico, aumentam a capacidade de condução pela ampliação da região de nervura e redução da distância de transporte. Desta maneira, se a superfície de transpiração é reduzida, simultaneamente, a área do sistema condutor é aumentada.

Os resultados obtidos no presente estudo permitem demonstrar as alterações ocorridas na estrutura das folhas dos indivíduos de P. lambertii, quando de sua exposição à contaminação do solo por petróleo. Constatou-se a redução na área foliar, maior densidade estomática, maior espessura total e do parênquima paliçádico. Fahn \& Cutler (1992); Burrows (2001); Lyshede (2002); Rhizopoulou \& Psaras (2003) identificam estas características como estratégias para aumentar a resistência contra a perda de água, o que poderia estar também ocorrendo nos indivíduos de $P$. lambertii das áreas submetidas à poluição.

\section{Agradecimentos}

Os autores agradecem à Dra. Solange Cristina Mazzoni-Viveiros, do Instituto de Botânica de São Paulo; ao Centro Universitário Positivo (UnicenP); à Universidade Federal do Paraná (UFPR), Departamento de Engenharia Florestal, Curitiba, Paraná, Brasil.

\section{Referências bibliográficas}

Baek, K.H.; Kim, H.S.; Oh, H.M.; Yoon, B.D.; Kim, J. \& Lee, I.S. 2004. Effects of crude oil, oil components, and bioremediation on plant growth. Journal Environmental Science and Health 39: 2465-2472.

Balaganskaya, E.D. \& Kudrjavtseva, O.V. 1998. Change of the morphological structure of leaves of Vaccinium vitisidaea caused by heavy metal pollution. Chemosphere 36: 721-726.

Bell, P.R. \& Hemsley, A.R. 2000. Green plants - Their origin and diversity. $2^{\text {nd }}$ ed. Cambridge, Cambridge University Press.

Berlyn, G.P. \& Miksche, J.P. 1976. Botanical microtechnique and cytochemistry. Iowa, Iowa University.
Bona, C. \& Santos, O.G. 2003. Adaptações fisiológicas de espécies vegetais crescendo em solo contaminado com petróleo. Curitiba, FUNPAR-UFPR.

Burrows, G.E. 2001. Comparative Anatomy of the Photosynthetic Organs of 39 Xeromorphic Species from Subhumid New South Wales, Australia. International Journal of Plant Sciences 162: 411-430.

Buvat, R. 1989. Ontogeny, cell diferentiation and structure of vascular plants. Berlin, Springer-Verlag.

Dorn, P. H. \& Salanitro, J. 2000. Temporal ecology assessment of oil contaminated soils before and after bioremediation. Chemosphere 40: 419-426.

Dorn, P. H.; Vipon, T.; Salanitro, J. \& Wisniewsky, H. 1998. Assessment of the acute toxicity of crude oils using earthworms, microtox and plants. Chemosphere 37: 845-860.

Ekundayo, E.O.; Emede, T.O. \& Osayande, D.I. 2001. Effects of crude oil spillage on growth and yield of maize (Zea mays L.) in soils of midwestern Nigeria. Plant Foods Hum. Nutr. 56: 313-324.

Esau, K. 1985. Anatomia vegetal. $3^{\text {rd }}$ ed. Barcelona, Omega.

Esau, K. 1998. Anatomia das plantas com sementes. $14^{\text {th }}$ ed. São Paulo, Edgard Blücher.

Fahn, A. \& Cutler, D. 1992. Xerophytes. Berlin, Gebrüder Borntraeger.

Fahn, A. 1990. Plant anatomy. $4^{\text {th }}$ ed. Oxford, Pergamon Press.

Feder, N. \& O'brien, T.P. 1968. Plant microthecnique: some principles and new methods. American Journal of Botany 55(1): 123-142.

Feller, I.C. 1996. Effects of nutrient enrichment on leaf anatomy of dwarf Rhizophora mangle L. (Red Mangrove). Biotropica 28: 13-22.

Ferdinand, J.A.; Fredericksen, T.S.; Kouterick, K.B. \& Skelly, J.M. 2000. Leaf morphology and ozone sensitivity of two open pollinated genotypes of black cherry (Prunus serotina) seedlings. Environmental Pollution 108: 297-302.

Franklin, G.L. 1946. A rapid method of softering wood for microtome sectioning. Tropical Woods 88: 35 .

Freedman, B. 1995. The ecological effects of pollution disturbance and stresses. Environmental ecology. $2^{\text {nd }}$ ed. São Diego, Academic Press.

Gifford, E.M. \& Foster, A.S. 1998. Morphology and evolution of vascular plants. $3^{\text {rd }}$ ed. New York, Freeman and Company.

Griffith, M.M. 1957. Foliar ontogeny in Podocarpus macrophyllus with special reference to the transfusion tissue. American Journal of Botany 44: 705-715.

Hernandez-Valencia, I. \& Magger, D. 2003. Uso de Panicum maximum y Brachiaria brizantha para fitorremediar suelos contaminados con un crudo de petróleo liviano. Bioagro 15(3): 149-155.

Hester, M.W. \& Mendelssohn, I.A. 2000. Long-term of a Lousiana brackish marsh plant community from oil spill impact: vegetation response and mitigating effects of marsh surface elevation. Marine Environmental Research 49: 233-254. 
Huesemann, H.M. 1994. Guidelines for land-treating petroleum hydrocarbon-contaminated soils. Journal Soil Contaminate 3: 299-318.

Inoue, M.T. \& Reissmann, C.B. 1993. Efeitos da poluição na fotossíntese, dimensões da folha, deposição de particulados e conteúdo de ferro e cobre em alfeneiro (Ligustrum lucidum) da arborização urbana de Curitiba, PR. Floresta 21: 3-11.

Johansen, D.A. 1940. Plant microtechnique. New York, Mc Graw Hill Book Company, Inc.

Klich. M.G. 2000. Leaf variations in Elaeagnus angustifolia related to environmental heterogeneity. Environmental and Experimental Botany 44: 171-183.

Kozlowski, T.T. \& Pallardy, S.G. 1997. Physiology of woody plants. San Diego, Academic Press.

Kozlowski, T.T.; Kramer, P.J. \& Pallardy, S.G. 1991. The physiological ecology of woody plants. San Diego, Academic Press.

Kraus, J.E. \& Arduim, M. 1997. Manual básico de métodos em morfologia vegetal. Edur, Rio de Janeiro.

Kürschner, W.M.; Stulen, I.; Wadner, F. \& Kuiper, P.J. 1998. Comparison of Paleobotanical Observations with Experimental Data on the Leaf Anatomy of Durmast Oak, Quercus petraea (Fagaceae) in Response to Environmental Change. Annals of Botany 81: 657-664.

Larcher, W. 2000. Ecofisiologia vegetal. São Carlos, Rima Artes e Textos.

Lee, C.L. 1952. The anatomy and ontogeny of the leaf of Dadrydium taxoides. American Journal of Botany 39: 393-398.

Lereder, B. 1955. Vergleichende untersuchungen über das transfuions-gewebw einiger rezenter Gymnospermen Botany Studien Heft 4: 1-42.

Lin, Q. \& Mendenssohn, I.A. 1998. The combined effects of phytoremediation and bioestimulation in enhancing habitat restoration and oil degradation of petroleum contaminated wetlands. Ecology Engineering 10: 263-274.

Lyshede, O.B. 2002. Comparative and functional leaf anatomy of selected Alstroemeriaceae of mainly Chilean origin. Botanical Journal of the Linnean Society 140: 261-272

Macedo, N.A. \& Leite, K.R.B. 1999. Aspectos anatômicos da folha de Podocarpus lambertii Klotzsch (Podocarpaceae). Sitientibus 20: 23-31.

Martínez-Trinidad, T.; Vargas-Hernández, J.J.; López-Upton, J. \& Muñoz-Orozco, A. 2002. Response of Pinus leiophylla to Water Deficit: Biomass Accumulation, Development of Secondary Needles and Seedling Mortality. Terra 20(3): 291-301.

Mauseth, J.D. 1988. Plant anatomy. Menlo Park, Benjamin Cummings.

Michel, J., Henry Jr., C.B. \& Thumm, S. 2002. Shoreline assessment and environmental impacts from the M/T Westchester oil spill in the Mississippi River. Spill Science \& Technology Bulletin 7(3/4): 155-161.

Michel, J.; Trevor, G.; Waldron, J.; Blocksisidge, C.T.; Etkin, D.S. \& Urban, R. 2005. Potentially Polluting Wrecks in Marine Waters. Pp. 1-84. In: 2005 International Oil Spill Conference. Miami, Florida.
Momen, B.; Anderson, P.D. \& Helms, J.A. 1999. Temperature dependency of acid-rain effect on photosynthesis of Pinus ponderosa. Environmental Pollution 113: 223-230.

Musselman. R.C. \& Minnick, T.J. 2000. Nocturnal stomatal condutance and ambient air quality standards for ozone. Atmospheric Environment 34: 719-733.

O’Brien, T.P.; Feder, N. \& Mccully, M. 1965. Polychromatic staining of cell walls by toluidine blue. Protoplasma 59(2): 368-373.

Page, C.N. 1990. General Traits of Conifers: The Families and Genera of Vascular Plants In: K. Napp-Zinn (ed.). Anatomie des Blattes. I. Blattanatomie der Gymnospermen. Handbuch der Pflanzenatomie. $2^{\text {nd }} \mathrm{ed}$. Berlin, Bornträger.

Petukhov, V.N.; Fomchenkov, V.M.; Chugunov, V.A. \& Kholodenko, V.P. 2000. Plant biotests of soil and water, polluted with petroleum and petroleum products. Applied and Environmental Microbiology 36(6): 652-655.

Pezeshki, S.R.; Hester, M.W.; Lin, Q. \& Nyman, J.A. 2000. The effects of oil spill and clean up on dominant US ulf coast marsh macrophytes: A review. Environmental Pollution 108: 129-139.

Pothuluri, V.J. \& Cerniglia, E.C. 1994. Pp. 92-123. Microbial metabolismo f polycyclic aromatic hydrocarbons. In: R.G Chaudry (ed.). Biological Degradation and Biorremediation of Toxic Chemicals. Dioscorides. Portland.

Powell, R. 1997. The use of plants as "field" biomonitors. Pp. 47-61. In: W. Wang; J. Gorsuch \& J. Hughes (eds.). Plants for Environmental Studies. Lewis, Boca Raton.

Proffitt, E.; Devlin, J.D. \& Lindsey, M. 1995. Effects of oil on mangrove seedlings growth under different environmental conditions. Marine Pollution Bulletin 30: 788-793.

Rhizopoulou, S. \& Psaras, G.K. 2003. Development and Structure of Drought-tolerant Leaves of the Mediterranean Shrub Capparis spinosa L. Annals of Botany 92(3): 377-383.

Rivera-Cruz, M.C. \& Trujillo-Narcía, A. 2004. Estudio de toxicidad vegetal em suelos com petróleos nuevo e intemperizado. Interciencia 29(7): 369-376.

Rivera-Cruz, M.C.; Ferrera-Cerrato, R.; Volke, H.V.; Rodríguez, V.R. \& Fernández, L.L. 2002. Problación microbiana em perfiles de suelos afectados por hidrocarburos del petróleo en el estado de Tabasco. Agrociencia 36: 149-160.

Sakai, W.S. 1973. Simple method for differential staining of parafin embedded plant material using toluidine blue. Stain Technology 48: 247-249.

Sloan, N.A. 1999. Oil impacts on cold-water Marine Resources: A review relevant to Parks Canada's evolving Marine Mandate. Occasional Paper 11.

Spies, R.B.; Rice, S.D.; Wolpe, D.A. \& Wright, B.A. 1996. The effects of the Exxon Valdez oil spill on the Alaskan coastal environment. Pp. 1-16. In: Exxon Valdez Proceedings of the Exxon Valdez oil spill symposium. Bethesda. 
Strickland, R.M. 1990. The Pacific Northwest coast: fossil fuel frontier. Environment Journal 6: 25-77.

Woodward, F.I. 1987. Stomatal numbers are sensitive to increases in $\mathrm{CO}_{2}$ from pre-industrial levels. Nature 327: 617-618.
Xu, J.G. \& Johnson, R.L. 1995. Root growth, microbial activity and phosphatase activity in oil-contaminated, remediate and uncontaminated soils planted to barley and field pea. Plant Soil 173: 3-1. 